EESTI NSV TEADUSTE AKADEEMIA TOIMETISED. VII KOIDE

BIOLOOGILINE SEERIA. 1958, NR. 2

ИЗВЕСТИЯ АКАДЕМИИ НАУК ЭСТОНСКОИ ССР. ТОМ VII

СЕРИЯ БНОЛОГИЧЕСКАЯ. 1958, № 2

\title{
АНАЛИЗ РЕФЛЕКСА МОЛОКООТДАЧИ В УСЛОВИЯХ ОДНОСТОРОННЕЙ ДЕАФФЕРЕНТАЦИИ ВЫМЕНИ У КОЗ
}

\section{В. А. Вальдман}

Современная нейрогуморальная теория процесса молокоотдачи, разделяемая большинством исследователей, была выдвинута Эли и Петерсеном в 1940-1941 гг. Согласно этой теории, при сосании и доении возникают афферентные нервные импульсы, которые вызывают рефлекторное освобождение гормона неврогипофиза-окситоцина. Последний, поступая по кровеносному руслу в молочную железу, обусловливает сокращение миоэпителиальных элементов альвеол и изгнание молока в цистерну железы.

Авторы считают, что в нормальных условиях эфферентная иннервация железы не имеет существенного значения для регуляции скорости молокоотдачи.

Изучение дуги рефлекса молокоотдачи интенсивно проводилось в последние годы в лаборатории физиологии сельскохозяйственных животных Института физиологии им. И. П. Павлова АН СССР (Барышников и др., 1951, 1953). На основе полученных в лаборатории данных было высказано положение о двухфазности рефлекса молокоотдачи как у коров, так и у коз.

Гофман $(1953,1955)$ наблюдала у коз двухфазную реакцию молокоотдачи при доении или массажировании одной половины вымени. Так, через $1-5$ секунд после начала доения из противоположного катетеризуемого соска начинается усиленное выделение молока в виде частых капель. Вслед за этим, через определенный латентный период, вновь наступает усиление выделения капель молока, переходящих в струю (нейрогуморальная фаза). Принимая во внимание короткий латентный период первого учащения выделения капель молока, автор предполагает, что это учащение вызвано рефлексом на мускулатуру протоков, который осуществляется только нервным путем и носит сегментарный характер.

Для подтверждения справедливости этого предположения Г. Н. Павлов (1954) исследовал процесс молокоотдачи у коз в условнях локального охлаждения спинного мозга на уровне последнего грудного позвонка. В результате холодовой блокады дорзальных канатиков спинного мозга, вторая, нейрогуморальная фаза рефлекса исчезала, в то время как первая фаза рефлекса сохранялась, что, по мнению автора, свидетельствует о том, что рефлекс, обусловливающий первую фазу молокоотдачи, замыкается в сегментах спинного мозга, расположенных ниже зоны охлаждения.

Данные Гофман и Г. Н. Павлова, несомненно, представляют определенный интерес. Однако отсутствие в обеих работах контрольных опытов с денервацией молочной железы оставляет известные сомнения в том, обусловлено ли учащение капель в первые секунды доения сегментарной рефлекторной реакцией или же оно вызвано механическим перемещением катетеризуемой железы при доении.

До сих пор изучение роли афферентной иннервации молочной железы в регуляции моторной функции этого органа проводилось только в опытах с полной денервацией половины вымени. Это позволило получить первые ценные данные о роли афферентной иннервации молочной железы в осуществлении рефлекса молокоотдачи (Цахаев, 1951).

Однако оставалось неясным, вызваны ли наблюдающиеся в денервированной железе изменения функции моторного аппарата - повышение чувствительности к гуморальным агентам, изменение соотношения цистернальной и альвеолярной емкостей и т. д. - деэфферентацией или деафферентацией этого органа. Для того, чтобы ответить на этот вопрос, мы изучили в данной работе моторную функцию молочной железы в условиях ее деафферентации.

Желая получить новые данные о природе первой фазы рефлекса молокоотдачи у коз, мы исследовали также влияние деафферентации молочной железы, а в отдельных опытах и денервации этого органа на характер первой фазы рефлекса молокоотдачи. 


\section{Методика}

Опыты были поставлены в период с 1954 по 1956 г. на 13 лактирующих козах стада научно-опытной станции Института физиологии им. И. П. Павлова АН СССР. Наблюдения за рефлексом молокоотдачи проводились с помощью методики графической регистрации, описанной Г. Н. Павловым (1955).

В каждом опыте учитывался объем цистернальной и альвеолярной порций молока из правой и левой железы отдельно. Процент жира определялся в суточном количестве молока. Проводились следующие операции:

1) перерезка дорзальных корешков спинного мозга $\left(\mathrm{L}_{1}-\mathrm{L}_{5}\right)$ на левой стороне и перерезка промежностного'нерва на той же стороне;

2) односторонняя денервация вымени.

Для оценки полноты деафферентации и денервации использовались следующие пробы: 1) определение рефлекса молокоотдачи, 2) олределение болевой чувствительности кожи сосков и вымени, 3) определение интероцептивной чувствительности вымени по двигательной реакции животного в ответ на вдувание в вымя стерильного воздуха. После деафферентации и денервации чувствительность вымени, определяемая этими пробами, исчезла у всех коз.

\section{Результаты опытов}

В ґервой серии опытов был исследован рефлекс молокоотдачи у 9 интактных животных. Ход опыта заключался в следующем: в один из сосков вымени вв'ддися катетер, через который выпускалась цистернальная порция молока. Когда выделение капель молока из катетера становилось более или менее равномерным, начиналась дойка противоположного соска. Учитывался латентный период появления учащения капель молока (рефлекторная фаза рефлекса), а также латентный период появления струи молока (нейрогуморальная фаза).

Результаты опытов показали, что дойка одного соска вызывает молокоотдачу с обеих сторон, что согласуется с данными Гейнса (Gaines, 1915), Барышникова и др. (1951).

Что касается первой, так называемой рефлекторной фазы рефлекса молокоотдачи, то здесь у одних и тех же животных не наблюдалось определенной закономерности в появлении этого феномена. В одних случаях учащение капель молока начиналось в момент прикосновения к соску, без латентного периода (рис. 1a), в других - после $1-15$ секунд латентного периода (рис. 1б:

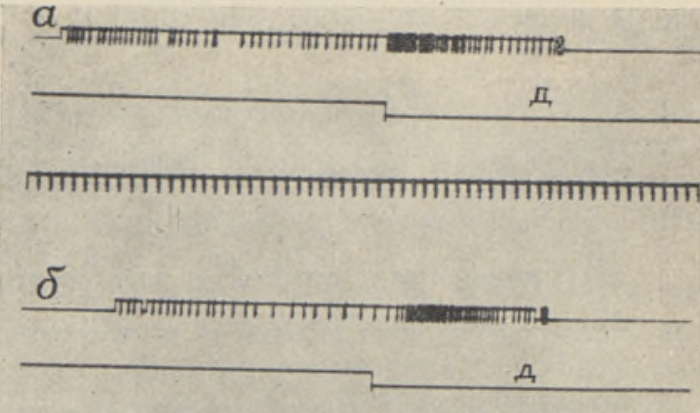

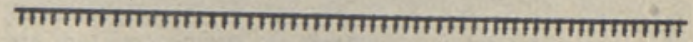
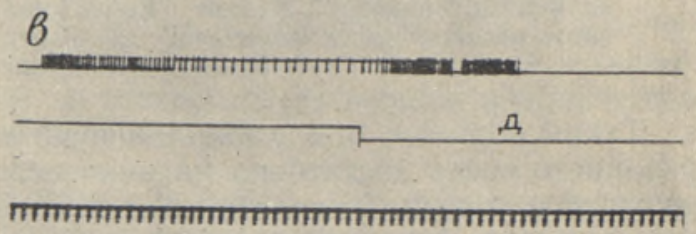

$\Gamma$

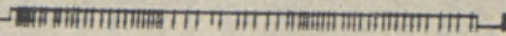

II,

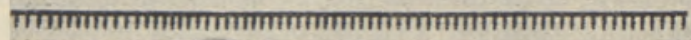

Рис. 1. Характер молоковыделения у козы Купавы. Опыты: $a-11$ VI 1955, б - 10 VII 1955, в -28 VI 1955, г - 25 VI 1955. Сверху вниз: молоковыделение из правого соска. Д - отметка дойки, отметка времени -2 сек. 
здесь латентный период - 6 секунд), в третьих - рефлекторную фазу невозможно было отделить от нейрогуморальной и учащение капель молока сразу переходило в струю (рис. 1в). В ряде опытов' у одних и тех же животных учащение выделения капель вообще отсутствовало, а через определенный латентный период молоко сразу выделялось струей (рис. 12).

\section{Рефлекс молокоотдачи после односторонней перерезки дорзальных корешков спинного мозга}

Односторонняя деафферентация молочной железы была осуществлена у 5 коз.

В результате односторонней перерезки дорзальных корешков спинного мозга наблюдались значительные изменения в процессе молокоотдачи. Так, при доении деафферентированной половины вымени, лишенной как экстеро-, так и интероцептивной чувствительности, не удалось наблюдать нейрогуморальной фазы рефлекса ни на оперированной, ни на интактной стороне, что, естественно, связано с потерей чувствительности вымени. При доении этой же деафферентированной железы у всех 5 коз, как правило, наблюдалось на противоположной стороне учащение выделения капель молока, то есть картина, напоминающая феномен рефлекторной фазы процесса молокоотдачи (рис. 2).

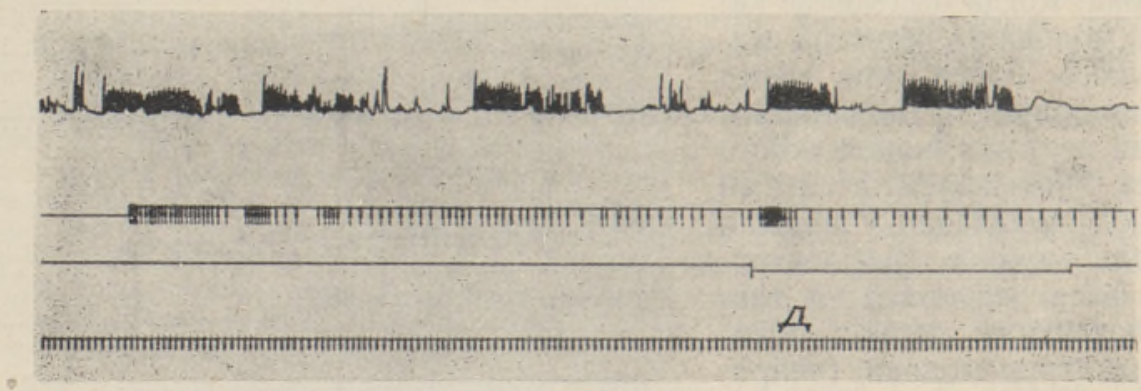

Рис. 2. Молоковыведение из нормальной половины вымени при доении деафферентированной железы. Коза Зорька. Опыт 16 IV 1954 г. Сверху вниз: жвачка, молоковыведение из правого соска, Д - отметка дойки, отметка времени - 2 сек.

Таким образом, при дойке лишенного чувствительности деафферентированного соска достаточно механического перемещения вымени, чтобы из противоположной железы вытекло несколько капель молока и была получена картина, напоминающая первую фазу рефлекса молокоотдачи.

При доении интактной половины вымени молокоотдача наступала и на деафферентированной половине железы. Однако характер рефлекса молокоотдачи на оперированной стороне изменился: латентный период нейрогуморальной фазы рефлекса уменьшился.

Уменьшение латентного периода рефлекса молокоотдачи вызвано деафферентацией железы, а не какими-либо другими причинами (операционная травма, стадия лактации и т. д.), так как на правой, контрольной стороне латентный период рефлекса молокоотдачи остался без изменений. Укорочение латентного периода наблюдалось у всех 5 животных (табл. 1).

В дальнейшем на тех же 5 козах нами были изучены латентные периоды молокоотдачи при введении извне суммарной вытяжки из нейрогипофиза-питуитрина. Мы пользовались питуитрином Московского завода 
эндокринных препаратов, ампульный раствор которого содержит $3 \mathrm{ME}$ окситоцина в 1 мл.

Таблица 1

Изменение латентного периода рефлекса молокоотдачи после деафферентации левой молочной железы

(Средние данные по 10 опытам)

\begin{tabular}{|c|c|c|c|c|}
\hline \multirow{2}{*}{ Кличка козы } & \multicolumn{2}{|c|}{$\begin{array}{c}\text { Латентный период рефлекса } \\
\text { молокоотдачи до операции } \\
\text { (сек.) }\end{array}$} & \multicolumn{2}{|c|}{$\begin{array}{l}\text { Латентный период рефлекса } \\
\text { молокоотдачи после операции } \\
\text { (сек.) }\end{array}$} \\
\hline & правая железа & левая железа & правая железа & $\begin{array}{l}\text { левая (деаффе- } \\
\text { рентирован- } \\
\text { ная) железа } \\
\end{array}$ \\
\hline $\begin{array}{l}\text { Кита } \\
\text { Маша } \\
\text { Зорька } \\
\text { Дыня } \\
\text { Дочка }\end{array}$ & $\begin{array}{l}49 \\
37 \\
43 \\
35 \\
28\end{array}$ & $\begin{array}{l}51 \\
38 \\
41 \\
34 \\
28\end{array}$ & $\begin{array}{l}51 \\
38 \\
42 \\
36 \\
30\end{array}$ & $\begin{array}{l}45 \\
33 \\
35 \\
28 \\
23\end{array}$ \\
\hline
\end{tabular}

До деафферентации введение питуитрина вызывало одинаковый молоковыделительный эффект как по времени, так и по силе в обеих половинах вымени.

Совершенно иная картина наблюдалась после деафферентации половины вымени. У всех коз деафферентированная половина вымени реагирует быстрее нормальной. Минимальные дозы питуитрина $(0,2$ мл), которые не вызыв'али молоковыделения из нормальной железы, оказались эффективными на деафферентированной половине.

Изменение чувствительности мускулатуры молочной железы после деафферентации было установлено далее и в опытах с применением адреналина. Введенный извне адреналин вызывает торможение молоковыведения. После деафферентации адреналин вызвал торможение молоковыведения на деафферентированной стороне в дозе 1,2 мл ампульного раствора, в то время как для того, чтобы вызвать торможение на интактной половине, этой дозы оказалось недостаточно.

Деафферентация не вызвала изменения соотношения между цистернальной и альвеолярной порциями молока на оперированной стороне. Удой и процент содержания жира в деафферентированной половине вымени по сравнению с контрольной не изменился.

Односторонняя денервация вымени. В целях дальнейшего анализа природы первой фазы рефлекса молокоотдачи проводились опыты с изучением рефлекса молокоотдачи у 5 коз с полной денервацией одной половины вымени. Эксперименты показали, что при доении соска денервированной половины вымени нейрогуморальная фаза рефлекса молокоотдачи отсутствует, но наблюдается учащение выделения капель молока из катетеризированного соска интактной железы (рис. 3). Это свидетельствует о том, что даже при дойке денервированного соска механическое перемещение вымени является достаточным для того, чтобы вызвать учащение каплевыделения из противоположной железы, напоминающее первую фазу рефлекса молокоотдачи. Доение интактной половины вымени также вызывало учащение выделения капель молока из денервированной железы, т. е. картину, напоминающую первую фазу рефлекса. Вслед за учащением, через определенный латентный период, начиналась нейрогуморальная фаза рефлекса, выражающаяся в выделении молока струей. 


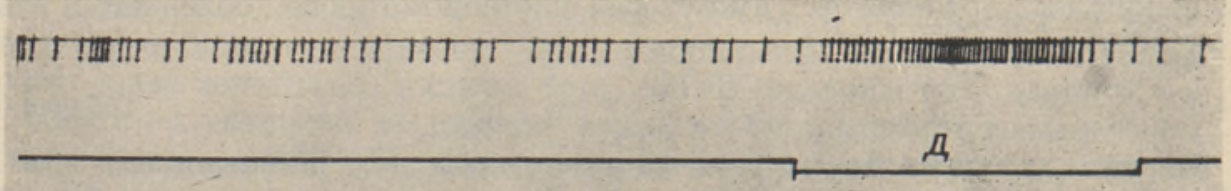

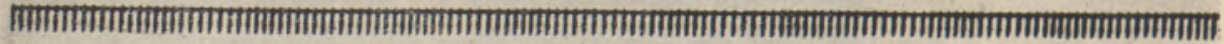

Рис. 3. Молоковыведение из интактной половины вымени при доении денервированной стороны вымени. Коза Дыня. Опыт 8 VIII 1955 г. Сверху вниз: жвачка, молоковыведение из правого (интактного) соска, Д - отметка доения, отметка времени - 1 сек.

Как при доении интактной половины, так и при введении питуитрина извне наблюдалось укорочение латентного периода молокоотдачи на денервированной железе.

\section{Опыты с раздражением кожи основания соска индукционным током}

Одним из доказательств наличия первой фазы рефлекса молокоотдачи у коз являются опыты Г. Н. Павлова, в которых он наблюдал усиление молоковыведения из одной или обеих желез через 5-6 секунд после начала раздражения кожи основания соска индукционным током (Г. Н. Павлов, 1954). В этих опытах отсутствовала объективная регистрация движения животного. Поэтому остаются известные сомнения в том, действительно ли усиление молоковыведения через 5-6 секунд после начала раздражения соска вызвано рефлексом на мускулатуру протоков. Не вызван ли этот феномен перемещением вымени при движении животного в момент раздражения? Чтобы проверить эти данные Г. Н. Павлова, мы поставили на 4 козах опыты по изучению молоковыведения при раздражении кожи основания соска индукционным током пороговой силы с одновременной объективной регистрацией движений животного с помощью подвижного пола. Раздражение кожи основания соска индукционным током пороговой силы всегда вызывало у интактных животных усиленное выделение капель молока из обоих сосков вымени через $2-7$ секунд от начала раздражения, и, как правило, этот эффект сопровождался движением животного.

Раздражение индукционным током основания соска денервированной половины вымени оставалось без эффекта. В то же время раздражение током пороговой силы основания соска нормальной железы вызывало усиление выделения капель молока через 2-7 секунд от начала раздражения как из денервированной, так и из интактной половины вымени при одновременном движении животного. Результаты этой серии опытов позволяют сомневаться в том, что усиление молоковыведения после начала раздражения соска индукционным током пороговой силы вызвано рефлекторными влияниями на мускулатуру протоков молочной железы.

Весьма вероятно, что этот эффект вызван перемещением вымени при движении животного в момент раздражения. 


\section{Обсуждение результатов опытов}

Результаты опытов с односторонней перерезкой дорзальных корешков спинного мозга показывают, что при доении деафферентированной половины вымени выпадает нейрогуморальная фаза рефлекса молокоотдачи. При доении интактной половины вымени на деафферентированной стороне гуморальная фаза рефлекса наступает в среднем на 5-8 секунд раньше, чем на нормальной. Такое же различие в длительности латентных периодов наблюдается в' опытах с введением извне питуитрина. Введенный извне адреналин вызывает на деафферентированной стороне более сильное торможение молоковыведения, чем на контрольной.

Қаков же механизм влияния деафферентации на моторную функцию молочной железы? По этому поводу можно высказать следующие предположения.

1. Деафферентация может вызвать изменение чув'стительности сократительных элементов к гуморальным агентам.

2. Изменение латентного периода рефлекса молокоотдачи при доении нли введении извне питуитрина, возможно, объясняется нарушением рефлекторной регуляции тонуса (расслаблением) протоков и их устьев в результате деафферентации железы.

3. Не исключено, что указанные изменения длительности латентного периода наступают вследствие нарушения регуляции функции кровеносных сосудов молочной железы в связи с ее деафферентацией. Увеличение диаметра кровеносных сосудов и их проницаемости может способствовать более быстрому поступлению гуморальных агентов' из кровеносного русла к сократительным элементам молочной железы.

Следует отметить, что феномен усиленного выделения капель молока (рефлекторная фаза) сопровождается перемещением вымени вследствие доения, массажа или движения жив'отного.

Гофман (1953) и Астраханская (1955) утверждают, что после половинной денервации вымени, при доении интактной половины железы первая фаза рефлекса на денервированной стороне не наблюдается. Однако данные Гофман и Астраханской получены в эксперименте на 2 козах, у которых денервация половины вымени была проведена задолго до опыта. Недостатком их работы является отсутствие исходного фона рефлекса молокоотдачи до операции. Изучение этого фона совершенно необходимо, так как известно, что феномен рефлекторной фазы у отдельных коз отсутствует. Полученные нами факты и высказанное здесь соображение заставляют сомневаться в рефлекторной природе первой фазы рефлекса молокоотдачи у коз.

\section{Выводы}

1. После односторонней деафферентации вымени рефлекс молокоотдачи с данной половины вымени исчезает.

2. После деафферентации половины вымени латентный период рефлекса молокоотдачи при доении интактной железы уменьшается.

3. Чувствительность деафферентированной половины вымени к питуитрину и адреналину повышается.

4. Деафферентация не вызывает изменения удоя и жирности молока на деафферентированной стороне по сравнению с контрольной.

5. После деафферентации соотношение между цистернальной и альвеолярной порциями молока не изменяется.

6. Наличие первой фазы рефлекса молокоотдачи у коз вызывает серьезные сомнения и нуждается в дальнейшей экспериментальной проверке. 


\section{ЛИТЕРАТУРА}

А ст р ах анск ая Н. А., 1955. Значение нервной системы для развития и функции молочной железы. Диссертация. Л.

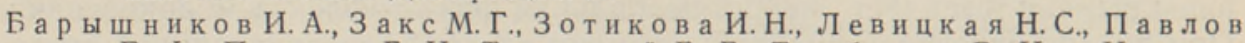
Е. Ф., П авлов Г. Н., Тв ерской Г. Б., Толбухин В. И. и Цеха ев Г. А., 1951. О нервной регуляции двигательной функции молочной железы (накопления молока и молокоотдачи). Журнал общ. биол., т. XII, № 6.

Б а р ы ш иков И. А., Бор сук В. Н., З акс М. Г., З Г. Н. и Т ол бухин В. И. 1953. К вопросу о нервной регуляции деятельности молочной железы. Журн. общ. биол., т. XIV, № 4.

Го фм ан М. А., 1953. Новые данные о рефлекторной регуляции молокоотдачи. Диссертация, Л.

Г о фм ан М. А., 1955. О рефлекторной регуляции лактации. Труды Инст. физиол. им. И. П. Павлова, т. IV.

П а в ло в Г. Н., 1954. Роль нервной системы в деятельности молочной железы. Диссертация. Л.

П а в лов Г. Н., 1955. К методике изучения нервной регуляции лактации. Труды Инст. физиол. им. И. П. Павлова, т. IV.

Ш а х а е в Г. А., 1951. Рефлекторная регуляция молокоотдачи. Диссертация. Л.

E ly, F. and Petersen, W. E., 1940. The Ejection of Milk from the Mammary Gland. J. Dairy Sci., vol. XXIII, No. 6.

E 1 y, F. and Peterse n, W. E., 1941. Factors Involved in the Ejection of Milk. J. Dairy Sci., vol. XXIV, No. 3.

G a ines, W. L., 1915. A Contribution of the Physiology of Lactation. J. Physiol., vol. 38.

Эстонский научно-исследовательский

институт животноводства и ветеринарии
Поступила в редакцию 7 IX 1957

\section{PIIMAEJEKTSIOONIREFLEKSI ANALUUS UDARA UHEPOOLSE DEAFERENTATSIOONI PUHUL KITSEDEL}

\section{Valdmann \\ Resümee}

Piimanäärme motoorse funktsiooni reguleerimisel on aferentse innervatsiooni osatähtsust katseliselt uuritud ainult täielikult denerveeritud udaral.

Senised katsed ei luba aga otsustada, kas denerveeritud udara juures täheldatavad motoorse funktsiooni muutused (tundilikkuse kōrgenemine humoraalsete agentide suhtes, udara tsisternaalse ja alveolaarse mahu suhte muutumine jne.) on tingitud selle organi deeferentatsioonist või deaferentatsioonist. Et saada täpsemaid andmeid piimanäärme aferentse innervatsiooni osatähtsuse kohta selle organi motoorses regulatsioonis, uuriti käesolevas töös udara motoorset funktsiooni deaferenteeritud piimanäärme juures.

Soovides saada uusi fakte piimaejektsioonirefleksi nn. esimese faasi mehhanismi kohta kitsedel, uuriti piimanäärme deaferentatsiooni ning eri katsetes ka denervatsiooni möju piimaejektsioonirefleksi esimesele faasile.

Esimeses katsete seerias täheldati pärast vasakpoolsete spinaalnärvide $\left(\mathrm{L}_{1}-\mathrm{L}_{5}\right)$ dorsaalsete juurte ja samapoolse perineaalnärvi läbilōikamist olulisi muutusi piimaejektsiooni protsessis. Deaferenteeritud udarapoole lüpsmisel ei täheldatud piimaejektsioonirefleksi neurohumoraalset faasi nii opereeritud kui ka intaktsel udarapoolel. Deaferenteeritud näärme lüpsmisel täheldati reeglipärast vastaspoolsest näärmest erituvate piimatilkade sagenemist, s. o. piimaejektsioonirefleksi esimese faasi pilti.

Piimaejektsioonirefleksi neurohumoraalse faasi latentsusperiood deaferenteeritud näärmel lühenes keskmiselt 5-8 sek. võrra. Piimanäärme deaferentatsiooniga kaasnesid ka muutused näärme motoorses funktsioonis, mis väljendusid väliselt näärme tundlikkuse tôusus parenteraalselt manustatud pituitriini ja adrenaliini suhtes.

Deaferenteerimine ei kutsunud opereeritud näärmes esile muutusi tsisternaalse ia alveolaarse piimahulga mahu suhtes. Samuti ei muutunud kontrollnäärmega võrreldes deaferenteeritud udarapooles piimahulk ja selle rasvaprotsent. 
Teises katsete seerias uuriti piimaejektsioonirefleksi nn. esimest faasi pärast udara ühe poole denervatsiooni. Katsed näitasid, et piimaejektsioonirefleksi esimest faasi täheldatakse intaktse udarapoole lüpsmisel ka denerveeritud näärmes ja denerveeritud vôi deaferenteeritud näärme lüpsmisel - intaktses näärmes.

Need faktid lubavad oletada, et piimaejektsioonirefleksi esimene faas seletub mitte reflektoorsete môjustustega piimajuhade muskulatuurile, vaid udara liikumisega lüpsmisel ja masseerimisel.
Eesti Loomakasvatuse ja Veterinaaria
Teadusliku Uurimise Instituut
Saabus toimetusse
7. IX 1957

\section{AN ANALYSIS OF THE REFLEX OF MILK-EJECTION IN CASE OF UNILATERAL DEAFFERENTATION OF GOATS' UDDER}

\section{Valdmann \\ Summary}

In the first series of experiments after dorsal radicotomy on the left side from $\mathrm{L}_{1}$ to $\mathrm{L}_{5}$ and sectioning of the perineal nerve on the same side, changes could be observed in the process of milk ejection. When milking the deafferented half of the udder the neurohormonal phase of the reflex of milk ejection was not noticed either on the operated or on the intact half of the udder. When milking the deafferented gland, as a rule, the excretion of milk drops from the opposite gland was noticed to become frequent, i.e. the picture of the phenomenon oi the first phase of milk ejection was observed.

The latent period of the neurohormonal phase of the reflex of milk-ejection by the deafferentated udder decreased by an average of $5-8 \mathrm{sec}$. The deafferentation of the mammary gland was accompanied by changes in the function of the motoric elements of the gland which manifested themselves in the increase of sensitiveness of the gland to parenterally administered pituitrine and adrenaline.

Deafferentation did not induce changes in the capacity of cisternal and alveolar milk in the gland of the operated side. The amount of milk and its fat content from the deafferented half of the udder did not change either, as compared with the control gland.

In the second series of experiments aiter unilateral denervation of the udder the phenomenon of the first phase of the reflex of milk ejection was observed in the denervated gland by milking the intact half of the udder, and also in the intact gland by milking the denervated or deafferentated gland.

From these facts we can suppose that the first phase of the reflex of milk ejection is explained not with reflectory influence upon the motoric elements of the milk ducts, but with the movement of the udder by milking and massage.
Estonian Scientific Research Institute for Stockbreeding and Veterinary 